\title{
RECENSIÓN DE LA OBRA «HESÍODO (SIGLO VIII A.C.)»
}

\author{
María Isabel Lorca Martín de Villodres*
}

Fecha de recibido: 25 de abril de 2013

Fecha de aprobado: 10 de junio de 2013

Recensión

Forma de citación: Lorca, M. I. (2013). Recensión de la obra «Hesíodo (Siglo VIII a.C.)». Revista Prolegómenos. Derechos y Valores, 16, 32, 247-250.

Volver nuestra atención hacia la lectura pausada y el estudio detenido de los clásicos resulta siempre enriquecedor, reconfortante, pero a la vez necesario, porque nos ayuda a tomar verdaderamente conciencia de que numerosos conceptos filosóficos y estructuras argumentativas, que son tenidas por modernas, encuentran sin embargo su fuente original en el caudal inagotable del pensamiento griego. Ello pone de manifiesto el impetuoso afán humano por desentrañar el origen primero de las cosas, ya existente de forma notable, en los albores del conocimiento, en donde se puede percibir-como la doctrina ha señalado con acierto- el tránsito del mito al logos, acaecido de manera paralela a la construcción paulatina de la filosofía como saber supremo, que toma su asiento en una racionalización de los mitos, y que tiene su causa postrera en el deslumbramiento del hombre en presencia de las cosas, y en la búsqueda incansable del por qué de los fenómenos.

En esta interesante obra aparecen condensados magistralmente los aspectos esenciales del pensamiento filosófico del poeta griego Hesíodo. El autor, el profesor doctor Sánchez de la Torre, estudia minuciosamente los poemas hesiódicos, principalmente Los trabajos y los días y el poema mitológico Teogonía, valiéndose de su profundo conocimiento de la filosofía y la filología griegas, lo que le lleva a perfeccio- nar las traducciones propuestas por anteriores autorizados filósofos, y asimismo nos expone con detalle los rasgos más sobresalientes de este poeta inspirado y pensador, que podría ser denominado con todo rigor, según los clásicos cánones de Grecia, como filósofo. Fue Hesíodo un antiguo pastor, hijo de un emigrante jonio, que vivió seguramente entre los siglos IX y VIII, y cuya obra poética, llena de riqueza literaria, permite establecer conexiones y llevar a cabo una comprensión global de los saberes contenidos en ella. En los poemas de Hesíodo descubrimos con asombro conceptos socio-jurídicos de gran relevancia que serán luego utilizados y propagados por destacados filósofos y juristas posteriores, pero que sin embargo deben su origen y autoría primera al eminente pensador griego. En efecto, Hesíodo, cuyo propio nombre puede ser traducido, como propone el profesor Sánchez de la Torre, como "camino que orienta en la búsqueda de algo" o "camino hacia la verdad", puede ser incluso conceptuado, en lo más profundo de su faceta filosófica, como un auténtico "creador de conceptos".

El profesor Sánchez de la Torre nos descubre la originalidad y alcance de esos mismos conceptos, así como los fundamentos filosóficos que sostienen los hermosos poemas de Hesíodo, quien a su vez se revela como el primer portavoz griego de temas de gran trascendencia

Profesora Titular de Filosofía del Derecho, Universidad de Málaga, España. Correo electrónico: misabellorca@gmail.com

Bogotá, D.C., Colombia - Volumen XVI - Núm. 32 - Julio - Diciembre 2013 - ISSN 0121-182X 
vinculados a la justicia y a la organización de la sociedad. Es decir, el autor nos explica todos aquellos conceptos de interés jurídico y de absoluta vigencia actual, que según los propios poemas, fueron revelados, bajo la forma de bello canto, a Hesíodo por las Musas Olímpicas, hijas de Zeus, mientras apacentaba a sus corderos en las laderas del divino monte Helicón.

La obra aparece claramente estructurada en cuatro grandes partes. En primer lugar, un cuadro cronológico, que ayuda al lector a ubicar temporalmente al filósofo griego analizado. En segundo lugar, el núcleo central de la obra, donde se estudia a Hesíodo como filósofo, que a su vez se subdivide en tres secciones. En efecto, en la primera sección, tras la sucinta exposición de unos interesantes rasgos biográficos, se aportan valiosos argumentos para calificar a Hesíodo como filósofo. En la segunda sección, se muestran los conceptos y doctrinas de alcance filosófico que aparecen en los poemas de Hesíodo. Y en la tercera, la exposición misma del sistema filosófico de Hesíodo, parte -según nuestra consideración- de gran relevancia doctrinal, pues muestra al lector, la posibilidad real de extraer de la obra de Hesíodo un auténtico y verdadero sistema tomando como punto de partida sus poemas, y que el profesor Sánchez de la Torre concibe bajo la siguiente división dotada de una gran coherencia lógica interna y de una absoluta concatenación mutua: Filosofía natural, Filosofía de la Religión y Antropología filosófica en Hesíodo, en donde precisamente se puede llegar a comprender la estrecha vinculación existente entre lo humano y lo divino, así como del hombre con el grupo social donde se inserta, según el pensamiento del propio Hesíodo. En la tercera parte de la obra encontramos una Selección de textos, que resultan de gran utilidad al lector para seguir adecuadamente el argumento doctrinal defendido en esta obra. Por último, en la cuarta parte hallamos la Bibliografía, que ha servido de apoyo al autor, y que nos muestra la gran riqueza y variedad intelectual de las fuentes consultadas.
En los poemas de Hesíodo descubrimos su doble condición de poeta y filósofo. Hesíodo es poeta porque escribe en versos hexámetros moldeando "poéticamente tanto los fenómenos descritos como el lenguaje que los expresa" -explica el profesor Sánchez de la Torre-. Hesíodo es filósofo porque "traduce el lenguaje mitológico a lenguaje ideológico, y a su vez ese lenguaje ideológico a lenguaje político, de tal modo que su poesía podría dar lugar a estudiar superestructuras ideológicas" -concluye el Catedrático de la Universidad Complutense de Madrid-. Siendo el objetivo primordial de Hesíodo distinguir entre la verdad y la falsedad o la apariencia de verdad. En efecto, en su Teogonía, las Musas proclamarán: "Sabemos decir muchas cosas engañosas, semejantes a las auténticas; y también sabemos, cuando lo deseamos, recuperar lo olvidado" (v. 27-28). Esa verdad hará posible la supervivencia de los hombres, ya que les permitirá distinguirla de las meras apariencias de verdad, podrán distinguir nada menos que la verdad del engaño. Hesíodo como filósofo estudia -como posteriormente Marco Tulio Cicerón denominaría en el libro V de sus Tusculanae- atentamente y con detenimiento la naturaleza de las cosas, analizando la génesis y el origen de los fenómenos (ex arkhés...ghéneto).

Es pues, Hesíodo un poeta filósofo, cuya filosofía es "natural" y su modo de describir la naturaleza es mitológico. Es más, podría afirmarse como indica el profesor Sánchez de la Torre que Hesíodo "utiliza precisamente la poesía de sus mitos para expresar contenidos propios del saber filosófico". En su planteamiento filosófico las referencias a la justicia y a la equidad son constantes. La justicia aparece contemplada de un modo, que podríamos calificar con toda prudencia, como "moderno", pues es concebida como "tratamiento igual". La teoría de la justicia de Hesíodo se sustenta sobre la tensión dialéctica de las nociones "caos" y "cosmos". Explica cómo las cosas alcanzan el orden a partir del desorden, elevándose Zeus en árbitro universal del ser y del no ser, cuyos dictámenes 
inspiran las leyes positivas, y donde los mensajes providenciales de las Musas son elemento esencial para alcanzar la armonía social. En la exposición poética y mitológica de Hesíodo se halla una argumentación jurídica bien construida, en donde la arbitrariedad o hýbris contrasta con el sentido de lo justo. Una idea de justicia que es ya expresiva de un orden racionalizador de la sociedad. De manera que semejante "camino poético se hace camino de salvación" para el ser humano en el orden terrenal, no en vano theogonía pudiera traducirse, según el profesor Sánchez de la Torre, como poema de los dioses creadores.

Estos argumentos hacen posible que el autor califique la filosofía de Hesíodo como filosofía existencial objetiva, porque es capaz de "explicar los eventos mediante su causalidad interna (génesis) y de explicar la realidad humana mediante los procesos de su actividad externa (trabajo para la supervivencia),... Sus poemas exponen una visión total del mundo humano. Presenta los dioses, los ancestros y los valores griegos, proyecta sobre el mundo creado y ordenado la medida de la dignidad humana (timé, aidós), articula sus modos de existencia en un ámbito convivencial de amplísima estructura (philía), ofrece un criterio igualitario para esa convivencia (tò eikés), e incluso diseña modos de existir donde pudiera germinar la felicidad...". Hesíodo construye, por tanto, una ética filosófica, que se estructura en torno al concepto de oikeîos (lo cercano, familiar, allegado,...), que servirá para la configuración de su noción de philía, elemento clave de lo que sería su filosofía social, cuya comprensión viene determinada por la existencia de una solidaridad fraternal entre seres humanos, en donde se produce también, al igual que entre el mundo de los dioses y los humanos, un intercambio de dones entre quienes lo necesitan.

Hasta tal punto que como explica el profesor Sánchez de la Torre, "no corresponder a un don recibido... constituye delito en términos de la solidaridad socialmente necesaria". Pero, a la vez, el mundo de lo humano se interaccio- na con el mundo divino muy íntimamente. La amistad o philía no es algo exclusivo del ámbito terrenal entre seres humanos. Aún situados en planos diferentes de la realidad, dioses y hombres se comunican fluidamente. El propio Hesíodo es capaz de distinguir lo verdadero de lo falso, el bien del mal, gracias a su consideración como "enviado de dios", como receptor de mensajes divinos. Los dioses eran estimados como donadores de bienes, así -como indica el profesor Sánchez de la Torre- en los últimos versos de Trabajos, los Inmortales otorgan sensata felicidad terrena a quienes respeten los mandatos divinos. Semejante generosidad tiene su explicación última en la creencia de que Zeus era considerado como "padre común de dioses y hombres".

Construye así Hesíodo una filosofía teológica, cuya base esencial la sitúa en la mutua philía o amistad entre dioses y seres humanos. La musa Calíope "otorga, a los que administran la justicia con decisiones correctas, la gracia de que se aplaquen los ánimos y que cada uno se conforme con lo suyo honradamente ganado". O, las hijas de Zeus y de Themis, las diosas "Eunomía, Diké y Eirene (buen gobierno, juicio justo, paz entre grupos) traen prosperidad... y regulan las obras de los mortales en provecho de todos". Se genera así un contexto teo-ándrico, donde la religión es una conexión vital para la philía entre dioses y humanos, y donde el ser humano está en conexión con el mundo sobrenatural del que precisamente participa "mediante los dones con que los dioses le agracian y de los agradecimientos con que él les corresponde". La filosofía de la Religión de Hesíodo cumple una elevada misión, cual es hacer posible, por tanto, que el hombre busque una primera explicación de los fenómenos que acontecen a su alrededor, generando la oportunidad de que el homo religiosus ascienda, desde la "mente natural" hacia la "mente cultural".

Pero Hesíodo también se detiene a estudiar la propia naturaleza humana, y nos ofrece en conformidad a la mentalidad mitológica de su época una explicación de la misma. El ser 
humano en el pensamiento de Hesíodo es contemplado dentro de un proceso evolutivo creador de los Dioses Olímpicos. Su evolución a través de las razas de los Oros, los Platas, los Bronces, los Héroes, hasta la llegada de los Hierros, que se correspondería con la raza de humanos que ahora habita la tierra, muestra el afán del eminente poeta griego de explicar la naturaleza humana en su complejidad y en íntima conexión con los dioses. En efecto, explica el profesor Sánchez de la Torre que los Hierros serían los humanos actuales "su destino está abierto hacia el futuro, alentado por la Esperanza, enderezado por las necesidades, inspirado por su libertad, servido por su laboriosidad, y ayudado por los mensajes divinos que les proponen modelos de la conducta que les haya de servir para el propio bien y para el bienestar común".

En esta obra se desgranan a lo largo de su casi centenar de páginas las claves esenciales para la comprensión del pensamiento filosófico de Hesíodo. En ella el autor muestra su profundo conocimiento de la filosofía griega, y mediante un lenguaje sencillo, cercano al lector, aunque no exento de gran erudición, realiza un recorrido ágil y minucioso por la poesía de Hesíodo, poniendo de manifiesto la sólida estructura filosófica que la caracteriza y extrayendo sus consecuencias más notables.
El libro, por su carácter formativo, es de gran interés para el filósofo, y en particular para el filósofo del derecho, pues pone especialmente el acento en cuestiones de gran repercusión jurídica que han pasado desapercibidas a eminentes autores anteriores que han estudiado el pensamiento del filósofo griego. Pero, tras la atenta lectura de esta obra lo que nos parece más revelador es detectar que conceptos que han sido abordados y desarrollados por filósofos posteriores a Hesíodo, encuentran sin embargo su origen y primer tratamiento doctrinal en este poeta griego. Así, la luminosa noción de philía o amistad, que es clave para la construcción del moderno concepto de Estado social, asentado en la solidaridad de las relaciones entre los ciudadanos, y que fue tratada detenidamente por Aristóteles (siglo IV a.C.), aparece ya abordada por vez primera en la poesía de Hesíodo (siglo VIII a. C.).

Por todas estas razones expuestas, y por su profundo contenido filosófico-jurídico y así como por su rigor sistemático, esta obra merece de ser destacada entre las que aparecen publicadas en nuestro panorama cultural actual.

\section{REFERENCIA}

Sánchez, Á. (2012). Hesíodo (siglo VIII a.C.). Madrid: Ediciones Clásicas, Ediciones del Orto. Biblioteca Filosófica, Núm. 145. 